\title{
Practice of Preventive Dentistry among Private Dental Professionals in Chennai-A Questionnaire Survey
}

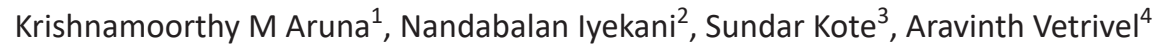

\begin{abstract}
Aim and objective: To assess the practice of preventive dentistry among the private dental professionals in Chennai.

Materials and methods: A cross-sectional questionnaire survey was conducted among the private dental practitioners in Chennai. A sample size of 200 private dental practitioners was randomly selected. Percentage responses were calculated and mean percentages were obtained.

Results: Of 200 dentists, only 120 responded (response rate $=60 \%)$. The majority of the respondents were MDS holders $(60.8 \%)$ and also the majority had experience in private practice for about 1-10 years (60\%). The desirable practices followed are self-applied fluoride, pit-andfissure sealant, oral hygiene measures, recall reinforcement, tobacco cessation counseling, screening for a premalignant lesion, and preventive orthodontics. The undesirable practices are diet counseling, professional fluoride application, and nicotine replacement therapy. Most of the dentists opted for preventive measures, only on a risk basis and in cases of absolute indications, thereby giving a desirable response.

Conclusion: The study concluded that the practice of preventive measures was encouraging and toward a path of change. Constant efforts must be made by the private dental practitioners to create a path along with preventive dentistry.

Keywords: Dental caries, Malocclusion, Oral cancer, Periodontal disease, Preventive dentistry.

Journal of Oral Health and Community Dentistry (2021): 10.5005/jp-journals-10062-0088
\end{abstract}

\section{INTRODUCTION}

Preventive dentistry is now considered the foundation of modern dental practice. ${ }^{1}$ Although prevention of diseases is a dream that can be realized only by the combined action of the dentist, patient, and community, dentists play a lead role. $^{2}$

Dentists' clinical decision influences the oral health and the overall health of the population. Therefore, dentists are increasingly being expected to apply preventive measures in their daily routine practice. However, some dentists seem to underestimate preventive measures and risk-based approaches in their practice. ${ }^{3}$

With regard to the current burden of oral diseases in India, it is recommended that a sharper focus on oral health promotion programs based on the recently developed concept of preventive oral care is much needed. ${ }^{4}$

A dentist must have a thorough idea about the usage of available preventive measures. A very little idea exists about the views of dentists on prevention and also about the practice and the ability to deliver preventive dental measures to their patients in a cost-effective manner. ${ }^{4}$

There exists a lack of data on the opinion of Indian dentists regarding the practice of preventive dentistry. ${ }^{4}$ Hence, the present study aims to analyze the practice of preventive dentistry among the private dental practitioners in Chennai, India.

\section{Materials and Methods}

A cross-sectional questionnaire study was conducted among the private dental professionals in Chennai. Chennai city was divided into five regions; central, northern, southern, eastern, and western. The dentists were selected by random sampling from each region. The survey was conducted for a period of 4 months, during the month of June 2019 to September 2019.

The study was approved by the ethics committee of Madha Dental College and Hospital.

\footnotetext{
${ }^{1-4}$ Department of Public Health Dentistry, Madha Dental College and Hospital, Chennai, Tamil Nadu, India
}

Corresponding Author: Krishnamoorthy M Aruna, Department of Public Health Dentistry, Madha Dental College and Hospital, Chennai, Tamil Nadu, India, Phone: +919003251880, e-mail: arunakmurali97@ gmail.com

How to cite this article: Aruna KM, lyekani N, Kote $S$, et al. Practice of Preventive Dentistry among Private Dental Professionals in Chennai-A Questionnaire Survey. J Oral Health Comm Dent 2021; 15(2):45-48.

Source of support: Nil

Conflict of interest: None

A total of 20 questions were framed, and most of them were close-ended questions, except the name and the age of the participant. The questionnaire used for the survey was pretested, validated, and customized before administration.

\section{Questionnaire Structure}

The questionnaire contained 20 questions which was divided into five sections. First section includes the demographic details of the participants, second section about the practice of preventive care for dental caries, third section pertaining to the practice of preventive care for periodontal disease, fourth section regarding the practice of preventive care for oral cancer, and fifth section about the practice of preventive care for a malocclusion.

\section{Study Sample}

Prior to the main study, a pilot study was conducted among 50 dentists to evaluate the questionnaire for any flaws and also to check for the validity and reliability of the questions. Consent was obtained from the participants who accepted to participate in the survey. 
The study aimed to include about 200 private dental practitioners in Chennai and the 200 dentists were selected through random sampling, and the questionnaire was distributed personally by the chief investigator and also shared through Google forms.

\section{Inclusion Criteria}

Private dental practitioners, consultant dentists, private dental practitioners attached to an academic institution, and dentists who volunteered to participate in the survey were included in the study.

\section{Exclusion Criteria}

Nonpracticing dental academicians, dentists those unwilling to participate in the study, and dentists who did not respond even after two reminders were excluded.

\section{Questionnaire Administration}

The questionnaire was administered to the dentists in person by the chief investigator and also the website link was shared through Google forms so that it could cover a wide range of dentists in Chennai. The purpose of the study and also the procedure to fill the form wereexplained to the participants.

The private practitioners were requested to fill it either at once or later within a week. The filled forms were collected in person by the principal investigator after a time period of one week. A reminder was sent to the dentists twice and follow-up was done. The dentists who did not respond even after two reminders were considered nonrespondents. Some of them could not respond because of their busy schedule.

\section{Data Analysis}

Two-option practice scale was classified as desirable (yes) and undesirable (no) response. Four-option practice scale was also classified as desirable (all patients, if indicated, patients at risk) and undesirable response (sometimes, never).

The mean percentages were calculated.

\section{RESULTS}

Of the 200 participants, only 120 private dental practitioners responded. The response rate of the study was $60 \%$.

\section{Demographic Data}

Of 120 respondents, the majority of the respondents were men (55\%) and women constituted about $45 \%$. Majority of the respondents were MDS holders (60.8\%) and BDS holders constituted about $37.5 \%$. Majority of the respondents had a private clinical experience of around $1-10$ years (60\%) and the least being respondents above 20 years of clinical experience (5\%).

\section{Practice of Preventive Measures for Dental Caries}

The most desirable practice among the respondents was prescribing patients the use of self-applied topical fluorides And $77.5 \%$ of the respondents prescribed self-applied topical fluorides, of which majority of them (66.6\%) preferred only fluoride-containing toothpastes.

Also, $54.2 \%$ of the respondents gave diet counseling on an occasional basis. Pit-and-fissure sealant was one of the least desirable practices being followed by the private professionals. Only $39.2 \%$ of the respondents opted for pit-and-fissure sealant if it is indicated and $12.5 \%$ of the respondents never used the pit-and-fissure sealant in their private practice.
Table 1: Practice of preventive measures for dental caries

\begin{tabular}{|c|c|c|c|c|}
\hline \multirow[b]{2}{*}{ Q. No. } & \multirow[b]{2}{*}{ Questions } & \multirow[b]{2}{*}{ Choices } & \multicolumn{2}{|c|}{ Response } \\
\hline & & & $n$ & $\%$ \\
\hline \multirow[t]{4}{*}{5} & \multirow[t]{4}{*}{ Diet counseling } & All patients & 11 & 9.2 \\
\hline & & Patients at risk & 39 & 32.5 \\
\hline & & Sometimes & 65 & 54.2 \\
\hline & & Never & 5 & 4.1 \\
\hline \multirow[t]{4}{*}{6} & \multirow{4}{*}{$\begin{array}{l}\text { Pit-and-fissure } \\
\text { sealant }\end{array}$} & If indicated & 47 & 39.2 \\
\hline & & $\begin{array}{l}\text { Patients with early } \\
\text { lesion }\end{array}$ & 30 & 25 \\
\hline & & Sometimes & 28 & 23.3 \\
\hline & & Never & 15 & 12.5 \\
\hline \multirow[t]{2}{*}{7} & \multirow[t]{2}{*}{ Topical fluoride } & Yes & 52 & 43.3 \\
\hline & & No & 68 & 56.7 \\
\hline \multirow[t]{5}{*}{8} & \multirow{5}{*}{$\begin{array}{l}\text { Self-applied } \\
\text { fluoride }\end{array}$} & Yes & 93 & 77.5 \\
\hline & & Toothpaste & 62 & 66.6 \\
\hline & & Mouthwash & 19 & 20.4 \\
\hline & & Both & 12 & 12.9 \\
\hline & & No & 27 & 22.5 \\
\hline
\end{tabular}

The most undesirable practice among the respondents was the use of topical fluorides, and $56.7 \%$ of the respondents do not use topical fluorides in their private practice.

Table 1 represents data on the practice of preventive measures for dental caries.

\section{Practice of Preventive Measures for Periodontal Disease}

About $43.3 \%$ of the respondents educate their patients about ideal brushing technique on an occasional basis. Only $33.3 \%$ of the respondents educate all their patients about ideal brushing technique. About $91.7 \%$ of the respondents demonstrate brushing techniques to their patients, of which $70 \%$ of the respondents use models to demonstrate the brushing technique to their patients.

Also, $57.5 \%$ of the respondents prescribe mouthwashes to their patients after oral prophylaxis, and $75.8 \%$ of the respondents prescribe interdental aids to their patients, out of which $47.2 \%$ of the respondents prescribe floss as an interdental aid.

Table 2 represents data on the practice of preventive measures for periodontal disease.

\section{Recall Reinforcement}

Majority of the respondents $(92.5 \%)$ recall their patients. Out of which $62 \%$ of the respondents recall their patients every 6 months and $7.5 \%$ of the respondents do not recall their patients.

Table 3 represents data on recall reinforcement.

\section{Practice of Preventive Measures for Oral Cancer}

About $68.3 \%$ of the respondents provide tobacco cessation counseling to all tobacco users, of which majority (48.9\%) of the respondents give tobacco cessation counseling only once and $70 \%$ of the dentists do not prescribe nicotine replacement therapy for their patients to quit tobacco.

And $87.5 \%$ of the respondents screen their patients for a premalignant lesion, of which majority of them (70.5\%) do only visual examination to screen for a premalignant lesion. 
Practice of Preventive Dentistry among Private Dental Professionals in Chennai

Table 2: Practice of preventive measures for periodontal disease

\begin{tabular}{|c|c|c|c|c|}
\hline \multirow[b]{2}{*}{ Q. No. } & \multirow[b]{2}{*}{ Questions } & \multirow[b]{2}{*}{ Choices } & \multicolumn{2}{|c|}{ Response } \\
\hline & & & $n$ & $\%$ \\
\hline \multirow[t]{4}{*}{9} & \multirow{4}{*}{$\begin{array}{l}\text { Educate about } \\
\text { ideal brushing } \\
\text { technique }\end{array}$} & All patients & 40 & 33.3 \\
\hline & & Patients at risk & 28 & 23.3 \\
\hline & & Sometimes & 52 & 43.3 \\
\hline & & Never & 0 & 0 \\
\hline \multirow[t]{6}{*}{10} & \multirow{6}{*}{$\begin{array}{l}\text { Demonstrate } \\
\text { brushing } \\
\text { technique }\end{array}$} & Yes & 110 & 91.7 \\
\hline & & Only model & 77 & 70 \\
\hline & & Only videos & 1 & 0.9 \\
\hline & & Only poster & 15 & 13.6 \\
\hline & & $\begin{array}{l}\text { Combinations } \\
\text { of above }\end{array}$ & 17 & 15.5 \\
\hline & & No & 10 & 8.3 \\
\hline \multirow[t]{4}{*}{11} & \multirow{4}{*}{$\begin{array}{l}\text { Prescribe } \\
\text { mouthwash }\end{array}$} & All patients & 7 & 5.8 \\
\hline & & After oral prophylaxis & 69 & 57.5 \\
\hline & & Sometimes & 39 & 32.5 \\
\hline & & Never & 5 & 4.2 \\
\hline \multirow[t]{6}{*}{12} & \multirow{6}{*}{$\begin{array}{l}\text { Prescribe } \\
\text { interdental aids }\end{array}$} & Yes & 91 & 75.8 \\
\hline & & $\begin{array}{l}\text { Interdental } \\
\text { brushes }\end{array}$ & 28 & 30.8 \\
\hline & & Floss & 43 & 47.2 \\
\hline & & $\begin{array}{l}\text { Water irrigation } \\
\text { devices }\end{array}$ & 2 & 2.2 \\
\hline & & More than one & 18 & 19.8 \\
\hline & & No & 29 & 24.2 \\
\hline
\end{tabular}

Table 3: Recall reinforcement

\begin{tabular}{|c|c|c|c|c|c|}
\hline \multirow[b]{2}{*}{ Q. No. } & \multirow[b]{2}{*}{ Questions } & & \multirow[b]{2}{*}{ Choices } & \multicolumn{2}{|c|}{ Response } \\
\hline & & & & $n$ & $\%$ \\
\hline \multirow[t]{5}{*}{13} & Recall & Yes & & 111 & 92.5 \\
\hline & reinforcement & & Every 3 months & 32 & 29 \\
\hline & & & Every 6 months & 69 & 62 \\
\hline & & & Every 1 year & 10 & 9 \\
\hline & & No & & 9 & 7.5 \\
\hline
\end{tabular}

Table 4 represents data on the practice of preventive measures for oral cancer.

\section{Practice of Preventive Measures for Malocclusion}

About $44.2 \%$ of the respondents advise habit-breaking appliances to their patients if it is indicated. Also, $42.5 \%$ of the respondents educate their patients regarding harmful habits if it is indicated, and $61.7 \%$ of the dentists follow up their patients regarding the eruption and shedding pattern of tooth.

Table 5 represents data on the practice of preventive measures for a malocclusion.

The desirable preventive dentistry practices followed are selfapplied fluorides, pit-and-fissure sealant, oral hygiene measures, recall reinforcement, tobacco cessation counseling, screening for a premalignant lesion, and preventive orthodontics. The undesirable preventive dentistry practices are diet counseling, professional fluoride application, and nicotine replacement therapy. The results are encouraging; however, more efforts need to be taken to move a step forward toward prevention.
Table 4: Practice of preventive measures for oral cancer

\begin{tabular}{|c|c|c|c|c|}
\hline \multirow[b]{2}{*}{ Q. No. } & \multirow[b]{2}{*}{ Questions } & \multirow[b]{2}{*}{ Choices } & \multicolumn{2}{|c|}{ Response } \\
\hline & & & $n$ & $\%$ \\
\hline \multirow[t]{2}{*}{14} & \multirow{2}{*}{$\begin{array}{l}\text { Tobacco } \\
\text { cessation } \\
\text { counseling }\end{array}$} & Yes & 82 & 68.3 \\
\hline & & No & 38 & 31.7 \\
\hline \multirow[t]{5}{*}{15} & \multirow{5}{*}{$\begin{array}{l}\text { How many } \\
\text { sessions of } \\
\text { tobacco } \\
\text { cessation } \\
\text { counseling? }\end{array}$} & Once & 45 & 48.9 \\
\hline & & Twice & 24 & 26.1 \\
\hline & & Thrice & 7 & 7.6 \\
\hline & & Four times & 0 & 0 \\
\hline & & Until they quit & 16 & 17.4 \\
\hline \multirow[t]{5}{*}{16} & \multirow{5}{*}{$\begin{array}{l}\text { Prescribe } \\
\text { nicotine } \\
\text { replacement } \\
\text { therapy }\end{array}$} & Yes & 36 & 30 \\
\hline & & Tablets/lozenges & 32 & 88.9 \\
\hline & & Patches & 3 & 8.3 \\
\hline & & Inhalers & 1 & 2.8 \\
\hline & & No & 84 & 70 \\
\hline \multirow[t]{6}{*}{17} & \multirow{6}{*}{$\begin{array}{l}\text { Screening for a } \\
\text { premalignant } \\
\text { lesion }\end{array}$} & Yes & 105 & 87.5 \\
\hline & & Visual examination & 74 & 70.5 \\
\hline & & Vital staining & 2 & 1.9 \\
\hline & & Biopsy & 15 & 14.3 \\
\hline & & More than one & 14 & 13.3 \\
\hline & & No & 15 & 12.5 \\
\hline
\end{tabular}

Table 5: Practice of preventive measures for malocclusion

\begin{tabular}{lllrr}
\hline & & & \multicolumn{2}{c}{ Response } \\
\cline { 3 - 5 } Q. No. & \multicolumn{1}{c}{ Questions } & \multicolumn{1}{c}{ Choices } & 53 & \multicolumn{1}{c}{$\%$} \\
\hline 18 & Habit-breaking & If indicated & 35 & 29.2 \\
& appliances & Risk of future & & \\
& & malocclusion & 27 & 22.5 \\
& & Sometimes & 5 & 4.1 \\
19 & Never & 51 & 42.5 \\
& Educate & If indicated & 35 & 29.2 \\
& consequences & Risk of future malocclu- & & \\
& of harmful & sion & 33 & 27.5 \\
& habits & Sometimes & 1 & 0.8 \\
20 & Follow-up & Yes & 74 & 61.7 \\
& $\begin{array}{l}\text { regarding } \\
\text { the shedding } \\
\text { and eruption } \\
\text { pattern of teeth }\end{array}$ & No & 46 & 38.3 \\
& & & \\
\hline
\end{tabular}

\section{Discussion}

Treatment-based approach has always been the scenario in case of private practice. With rising standards of education on preventive dentistry and constant efforts by the dentists in motivating patients more toward early treatment, practice of preventive dentistry can be established.

The response rate of the current study is $60 \%$, which is higher than that of Ramya et al. ${ }^{2}$ (57.8\%) and Patil et al., ${ }^{4}$ (55\%) and lower than that of Ghasemi et al..$^{5}(64 \%)$.

Majority of the respondents were MDS holders (60.8\%) and had an experience range of $1-10$ years (60\%), which revealed that 
young postgraduates had greater participation in the study and showed a positive sign toward the practice of preventive dentistry.

In the current study, $54.2 \%$ of the dental practitioners provided diet counseling only on an occasional basis. A study by Franki et al. ${ }^{6}$ showed a similar response that many dental practitioners provided either limited dietary advice or nothing at all. In contrast, studies by Saeed et al., ${ }^{1}$ Ramya et al., ${ }^{2}$ Janak et al., ${ }^{7}$ and Arheiam and Bernabe ${ }^{8}$ showed that diet counseling was better implemented.

Moreover, $39.2 \%$ of the dental practitioners provided pit-andfissure sealants to their patients if indicated. Dentist's negligence and patient's unawareness seem to be themajor cause. A study by Janak et al. ${ }^{7}(44.4 \%)$ and Patil et al. ${ }^{4}$ (73.4\%) showed a greater response.

In the current study, only $43.3 \%$ of the dental practitioners administered topical fluoride application to their patients. This is higher when compared to the study by Janak et al. ${ }^{7}(36.7 \%)$ and lower when compared to studies by Saeed et al.' (49.7\%) and Patil et al. $^{4}$ (83.2\%). The decline in the practice of topical fluorides is mainly due to the use of specialized materials and also the patient's objection to the preventive procedures.

Majority of the dentists prescribe self-applied topical fluorides (77.5\%), which is still lower than that shown by Saeed et al. ${ }^{1}$ Of which many prefer fluoride-containing toothpaste.

In this study, $91.7 \%$ of the dental practitioners demonstrate brushing technique to their patients. This is higher when compared to studies by Patil et al. ${ }^{4}$ (86.5\%). Many preferred to use models (70\%), which is similar to that of any other studies.

Majority of the dentists recall their patients for regular visits. In this study, about $92.5 \%$ of the dentists recall their patients, especially for every 6 months. This records to be the highest compared to studies by Patil et al. ${ }^{4}(88.3 \%)$ and Janak et al. ${ }^{7}(58.9 \%)$.

And $68.3 \%$ of the dentists in the study provided tobacco cessation counseling to their smoking patients, which is similar to the study by Janak et al. ${ }^{7}$ This is comparatively lower than those studies done by Saeed et al. ${ }^{1}$ (83.9\%) and Ramya et al. ${ }^{2}$ (65.85\%).

Only $30 \%$ of the dentists provide nicotine replacement therapy to their patients. Not many studies have spoken about the use of nicotine replacement therapy but this really seems to be less.

Majority of the dentists about $87.5 \%$ screen their patients for the presence of a premalignant lesion. This records to be the highest when compared to studies by Ramya et al. ${ }^{2}$ (84.15\%). Similar to any other studies, visual examination is the most preferred method (70.5\%).

In this study, $44.2 \%$ of the dental practitioners advise habitbreaking appliances to their patients. This is lower when compared to the study by Janak et al. ${ }^{7}$ (76.7\%). And $61.7 \%$ of the dentists in this study had recalled patients for follow-up regarding the shedding and eruption pattern of the tooth. A study by Janak et al. ${ }^{7}$ showed that $22.2 \%$ of the dentists do it for all their pediatric patients.
Less sample size is one major limitation of the study. It is highly recommended to carry out the study covering a larger area with a wide range of dentists so that better results could be arrived. As stated in other studies, the practitioners may give favorable responses rather than actual response, leaving the study biased.

\section{Conclusion}

The study conducted among the private dental professionals of Chennai laid down encouraging results. Preventive approach has found its path along the modern practice and constant efforts must be made to well establish it. However, there are downsides of the graph in cases of certain preventive approaches, like professional fluoride application and nicotine replacement therapy. The cost of preventive dentistry is almost the same as that of the curative approach. The dentists need to keep their patients well motivated and educate them about a preventionbased approach. This is where the private practitioners play a major role. The study results in urban areas, like Chennai, are, however, convincing. Similar studies must be carried out in rural areas to check out the exact scenario.

\section{References}

1. Saeed A, Suhaib F, Gul H, et al. Assessment of dentist's attitude and practice regarding preventive dentistry in teaching hospitals of Rawalpindi. Pak Oral Dental J 2015;36(4):610-614.

2. Ramya R, Ajithkrishnan CG, Thanveer K. Knowledge, attitude and practice of preventive dentistry among private dental practitioners in Vadodara, India. J Oral Health Comm Dent 2015;9(2)69-80. DOI: 10.5005/johcd-9-2-69.

3. Hadi Ghasemi. Dentists and preventive oral health care. In: Oral health care - prosthodontics, periodontology, biology, research and systemic conditions. February 2012. DOI: 10.5772/31993.

4. Patil YB, Kakodkar YB, Hegde-Shetiya S. Knowledge, attitude and practice amongst dentists in Pune towards primary preventive measures for dental caries-a questionnaire study. JIAPHD 2009;7(13):18-24.

5. Ghasemi $\mathrm{H}$, Murtomaa $\mathrm{H}$, Torabzadeh $\mathrm{H}$, et al. Determinants of oral health behavior among Iranian dentists. Int Dent J 2007;57(4):237-242. DOI: 10.1111/j.1875-595x.2007.tb00126.x.

6. Franki J, Hayes MJ, Taylor JA. The provision of dietary advice by dental practitioners: a review of the literature. Community Dent Health 2014;31(1):9-14. doi:10.1922/CDH_3297Hayes06

7. Janak $\mathrm{H}, \mathrm{Kumar}$, Bapilus $\mathrm{L}$, et al. Assessment of practice of preventive dentistry among oral health care professionals in chennai - a crosssectional survey.World J Pharmaceut Res 2018. DOI: 10.20959/ wjpr201811-12577.

8. Arheiam A, Bernabé E. Attitudes and practices regarding preventive dentistry among Libyan dental practitioners. Community Dent Health 2015;32(3):174-179. DOI:10.1922/CDH_3520Arheiam06 